\title{
Sociologia da Educação e construção de políticas educativas: da teoria à prática
}

Sociology of Education and Construction of Educational Policies: From the Theory to the Practice

\author{
João Sebastião, Luís Capucha, Susana Martins, Ana Rita Capucha'
}

\begin{abstract}
Resumo
A crescente complexidade no desenvolvimento de políticas públicas traduziu-se pelo aumento significativo no envolvimento de especialistas, muitos deles cientistas. Esse envolvimento é expresso de várias maneiras, seja através de solicitações de estudos preliminares, processos de planeamento ou avaliações da implementação e do impacto de medidas políticas. O desenvolvimento da relação entre os campos científico e político desafia o papel dos cientistas como especialistas e do uso do conhecimento científico, bem como as relações de poder entre políticos e cientistas. A sociologia da educação em Portugal tem uma longa tradição de interação com o campo político, não apenas em estudos relacionados ao desenvolvimento e avaliação de políticas educacionais, mas também em colaboração com escolas e outros provedores de educação em processos de intervenção e inovação socio-educacional. É uma experiência em que a natureza crítica e reflexiva da sociologia se cruza com a intervenção, num debate entre racionalidades e lógicas de ação diversas, colocando muitas vezes os sociólogos na posição de mediadores entre atores do sistema educacional com interesses frequentemente conflituantes e que comunicam mal ou não comunicam mesmo entre si. Com base na produção de um conjunto de estudos ordenados por diferentes entidades públicas portuguesas, foi realizada uma reflexão sobre os desafios teóricos, metodológicos e éticos colocados por esta colaboração, bem como sobre as possibilidades que dela resultam.
\end{abstract}

\section{Palavras chave}

Sociologia da educação, políticas de educação, expertise, sociologia pública.

\section{Abstract}

The growing complexity in public policy development has resulted in a significant increase in the involvement of experts, many of them scientists. This involvement is expressed in a variety of ways, whether through requests for preliminary studies, planning processes or evaluations of the implementation and impact of policy measures. The development of the relationship between the scientific and political fields challenges the role of scientists as experts and the use of scientific knowledge, as well as the power relations between politicians and scientists.

The sociology of education in Portugal has a long tradition of interaction with the political field, not only in studies related to the development and evaluation of educational policies, but also in collaboration with schools and other education providers in processes of intervention and socio-educational innovation. It is an experience in which the critical and reflexive nature of sociology intersects with intervention, in a debate between diverse rationalities and logics of action, often placing sociologists in the position of mediators among actors in the educational system with often-conflicting interests who miscommunicate, or do not even communicate with each other. Based on the production of a set of studies ordered by different Portuguese public entities, a reflection is presented on the theoretical, methodological and ethical challenges posed by this collaboration, as well as on the possibilities that result from it.

\section{Keywords}

Sociology of education, educational policy, expertise, public sociology.

\section{Cómo citar/Citation}

Sebastião, João; Capucha, Luís; Martins, Susana y Capucha, Rita Ana (2020). Sociologia da Educação e construção de políticas educativas: da teoria à prática. Revista de Sociología de la Educación-RASE, 13 (1), 7-19. http://dx.doi.org/10.7203/RASE.13.1.16225.

1 João Sebastião, joaoseb@sapo.pt; Luís Capucha, luis.capucha@iscte-iul.pt; Susana Martins, susana.martins@iscte-iul.pt; Ana Rita Capucha, anarita.capucha@gmail. com. Todos pertenecientes al Centro de Investigação e Estudos de Sociologia-Instituto Universitário de Lisboa. 


\section{Introdução}

A crescente mediatização de diversos temas da educação, sobretudo do sucesso e da qualidade do sistema educativo, da descentralização, da participação das famílias e das comunidades nas escolas, do currículo, entre outros, fruto da reivindicação de uma escola de massas em níveis superiores de escolaridade, em torno da qual se mobiliza um número crescente de atores sociais, políticos e económicos, tem contribuído para a configuração da agenda governamental (Bache, 2013), traduzindo-se, depois, na própria reformulação das políticas educativas nacionais. São exemplos disso: (1) a preocupação com as questões do insucesso escolar e a multiplicidade de medidas que têm, nos últimos anos, vindo a ser implementadas, quer ao nível geral (por exemplo, desenho dos currículos e apoios sociais), quer ao nível das práticas nas escolas (dimensão das turmas, práticas pedagógicas, organização do trabalho docente, etc.) e nas comunidades educativas; (2) a preocupação com a violência no contexto escolar, suscitando o surgimento de organismos responsáveis pela monitorização do fenómeno nas escolas e, consequentemente, pela orientação de políticas preventivas da violência; ou ainda, (3) o reconhecimento público dos instrumentos de autonomia e descentralização das escolas e da educação, particularmente aqueles que preveem um papel decisivo para a comunidade educativa (como as Cartas Educativas Municipais).

Neste contexto, a sociologia tem sido crescentemente convocada para o debate, o aprofundamento do conhecimento, a avaliação das políticas e, até, a assunção de responsabilidades políticas ao mais alto nível da governação (pelo menos em Portugal têm sido dezenas os sociólogos chamados a desempenhar cargos no governo e na direção da administração do sistema de educação). No presente artigo focamos a componente do envolvimento da sociologia na produção de conhecimento operacional em educação. São exemplo disso as encomendas de estudos preliminares, as avaliações da implementação e dos impactos de medidas políticas, ou a execução de tarefas de observação e monitorização dos seus efeitos no terreno e nas comunidades escolares, ou ainda a avaliação e autoavaliação das escolas.

O carácter crítico e reflexivo da produção sociológica cruza-se, assim, com o plano da intervenção, promovendo um encontro entre racionalidades diversas e colocando frequentemente os sociólogos na posição de mediadores entre atores que possuem interesses muitas das vezes conflituais e que pouco ou nada comunicam entre si. Importa, pois, refletir sobre a utilidade pública (Silva, 2017; Burawoy, 2009) da sociologia da educação, no âmbito da construção e/ou reformulação das políticas públicas educativas, ponderando, ainda, os diferentes desafios, potencialidades e/ou constrangimentos impostos à prática profissional dos sociólogos, através da explanação de exemplos práticos como os enunciados no início.

Abordaremos, neste artigo, um conjunto de exemplos de utilização pública da sociologia, com o objetivo de determinar, por um lado, a multiplicidade das formas que essa utilização assume, bem como, por outro lado, a coerência dos princípios que tendem a presidir, no plano da "perspetiva sociológica», aos vários exemplos aqui abordados.

\section{Ciências socias, conhecimento pericial e políticas públicas}

A progressiva complexidade na elaboração de políticas públicas nas sociedades contemporâneas, resultante de processos cruzados de diversificação e especialização institucional, dos avanços científicos e dos procedimentos conducentes à tomada de decisão num mundo globalizado e marcado pelo uso das tecnologias de informação e comunicação, teve como uma das consequências o aumento expressivo do recurso ao conhecimento técnico-científico de especialistas chamados a participar nos processos de 
desenho, gestão e avaliação das políticas públicas. A complexificação dos processos políticos e sociais tem contribuído para o aumento da importância que os peritos têm vindo a ocupar nas sociedades atuais (Beck, 1992; Giddens, 1992; Stehr, 1994, Fischer, 2009), daí resultando um conjunto de questões que não sendo novas, pois já Weber para elas tinha alertado, assumem agora novos contornos. A relação entre ciência e política questiona a intervenção dos cientistas, nomeadamente quanto ao seu papel enquanto peritos e ao uso que fazem quer do conhecimento científico, quer da autoridade associada ao estatuto de possuidores do saber pericial legítimo. Contudo esta participação na vida pública, frequentemente criticada pelo seu carater instrumental, deve ser, como referia a certa altura Coleman (1994), considerada uma questão central da sua atividade.

Face à pergunta que muitos colocam à sociologia e às ciências sociais em geral, sobre a sua utilidade pública, é hoje cada vez mais necessário sublinhar a sua importância na descodificação da complexidade da realidade social, proporcionado conhecimento e favorecendo processos reflexivos estruturados sobre as diversas e contraditórias facetas dessa realidade e dos modos como esta é interpretada de forma plural e controversa. A dominação social é também, e em primeiro plano, o resultado da dominação sobre a "interpretação verdadeira" do mundo, como salientava Bourdieu. A importância deste tópico tanto mais relevante quanto uma das principais características das interpretações e (re)conhecimentos comuns sobre as coisas, é a de serem reflexivas e capazes de utilizar a reflexão como mecanismo de ocultação dos seus próprios fundamentos, isto é, dos interesses dos quais são o produto. Uma das implicações do efeito de ocultação como fonte de legitimação das ideologias, é que a sociologia e as outras ciências sociais competem pelo reconhecimento da sua pertinência e validade científica, ao mesmo tempo que procuram colocar em perspetiva a diversidade de "explicações" socialmente interessadas no sentido de intermediar a relação entre os agentes que as produzem.

Partindo deste ponto, devemos desde logo assumir que a sociologia não esgota a sua virtualidade científica e reflexiva quando associada ao terreno da formulação de políticas públicas específicas (Silva, 2006; Ramos, Capucha e Tavares, 2018). Muito pelo contrário, é justamente na sua capacidade mediadora, na visão abrangente, na fundamentação e na convergência, que adquire um potencial transformador e inovador para o contexto das políticas, permitindo-lhe, depois, a consolidação da sua especialização científica sobre várias e diferentes matérias da política pública.

Importa, por isso, identificar sumariamente algumas questões que apontam, justamente, para a própria complexidade desta relação e que devem, por isso, ser objeto de reflexão:

1. por um lado, ter presente que a utilidade pública da sociologia é muito diversa, e a perícia profissional é apenas um entre vários papeis que esta ciência (e profissão) pode desempenhar, porventura aquele que mais aproxima o investigador da realidade onde ele próprio está inserido;

2. não obstante contribuir para leituras dinâmicas da realidade que permitem um quadro favorável à produção de políticas relevantes, não significa que a ciência constitua o centro da ação, ou que a sociologia atribua normatividade aos fenómenos sociais que interpreta;

3. grande parte da atividade pericial desenvolve-se por intermédio de questões críticas para o funcionamento das sociedades e, sobretudo, de problemáticas reconhecidas pela própria comunidade científica;

4. contudo, o próprio processo de construção da problemática científica (tornar um problema social 
num problema sociológico) é fortemente condicionado pelas agendas políticas, pelos financiamentos, por avanços e retrocessos de vária ordem;

5. a atividade pericial tem uma construção híbrida, pelo que incorpora conhecimento cientifico, peritagem técnica especializada, incluindo, ainda, contributos dos chamados «peritos leigos» (Maasen \& Weingart, 2005); desenvolve-se, assim, num espaço complexo e contraditório, já que incorpora evidências vindas de diferentes campos, com lógicas e processos de legitimação diversos, onde a negociação é permanente e os próprios limites da autonomia relativa da sociologia são questionados; por vezes, resultam ainda cenários de pareceres diametralmente opostos, o que acaba por gerar grande desconfiança face ao trabalho científico;

6. a legitimidade técnica confronta-se com a própria legitimidade política, alimentando o debate quanto à suposta neutralidade da atividade de peritagem, isto porque até à formulação do produto final são escassos os mecanismos e momentos de escrutínio democrático e público. Esta situação vê-se sobretudo com a utilização de pareceres jurídicos, estudos de avaliação ou preparatórios da elaboração de políticas públicas, sem que de facto estes mesmos pareceres e os fundamentos para as opções que sugerem, sejam, muitas das vezes, divulgados publicamente;

7. a atividade pericial incorpora uma dimensão paradoxal, produzindo fragilidades que se traduzem em limitações ao seu desenvolvimento e capacidade analítica, fruto de «uma permeabilidade entre saber e poder que não favorece o conhecimento sobre a realidade e muito menos a formação de alternativas políticas» (Rodrigues e Silva, 2012: 17-18);

8. apesar disso, de entre todas as linguagens sobre os processos políticos, a científica contínua a ser a mais apta para a produção de saberes objetivos, resultantes tanto da utilização do método científico, como da perspetiva obtida a partir de uma visão sistémica sobre os campos em que incidem as decisões, o que permite olhar para além das cortinas de fumo ideológicas produzidas pelos atores políticos e institucionais.

\section{O papel da sociologia da educação na (re)construção de políticas educativas}

A relação entre a sociologia e o campo da política acarreta inúmeros desafios, não apenas para o profissional de sociologia, que se vê agora num terreno cada vez mais colaborativo e interdisciplinar, mas inclusivamente para o próprio campo do policy-making educativo, dado que a urgência e a importância de uma boa parte das políticas educativas resulta, justamente, da relação/negociação que se estabelece entre: (1) entidades estatais (Ministério da Educação, Secretarias de Estado) e organismos da administração, com as suas preocupações em torno da eficiência e da eficácia das medidas políticas; (2) parceiros sociais e educativos (sindicatos, associações de pais ou de estudantes, etc.), com as diferentes agendas reivindicativas; (3) comunidade académica/científica, com os alertas, mediações, orientações e fundamentações; e finalmente, (4) opinião/debate público, que se sabe, entre outras coisas, determinante para os tópicos a incluir no agenda-setting da política educativa nacional.

São inúmeras as potencialidades que a sociologia oferece a um contexto de elaboração, desenho, ou de monitorização e avaliação de políticas. Entre outras, (1) contextualiza, disponibilizando um quadro lógico analítico que não é estanque, nem único, e que percorre diferentes tradições epistemológicas, desde correntes mais funcionalistas, às mais estruturalistas, ou às mais interacionistas e individualistas; (2) enriquecedora dos processos, uma vez que se especializa na monitorização, na análise processual e no enqua- 
dramento dos diferentes atores, cujos interesses procura interpretar, mediar e considerar; (3) reflexiva, já que desempenha um papel de suporte e de «background» crítico, tornando a própria política ou medida no seu objeto de estudo, significando isso que põe a descoberto as visões e interpretações conflituais, por vezes ocultadas pelos pesados aparelhos formais e burocráticos onde a política se desenrola; (4) carateriza criteriosamente e prioritariamente o domínio das medidas e políticas a implementar, apoiando-se numa investigação multietapas e multiescalar que envolve desde o diagnóstico, à auscultação de todas as partes interessadas, até, depois, ao domínio das recomendações finais; (5) e, finalmente, promove, abertamente, o debate público informado, rompendo com mitos e com o senso-comum, contribuindo para uma visão objetiva e sustentada da realidade múltipla que nos circunda.

Os exemplos que se seguem, retirados de um conjunto vasto de casos de envolvimento dos autores do presente texto em processos de elaboração e implementação de políticas de educação, são demonstrativos do potencial deste quadro interativo, mas também dos desafios e dificuldades inerentes ao próprio «backstage» onde o jogo da peritagem e da construção política acontece.

\section{a) Observatório de Segurança Escolar (OSE)}

A mediatização dos episódios de violência nas escolas portuguesas, ocorrida a partir do meio da década de 1990, conduziu a uma solicitação política para a criação de um observatório permanente de monitorização e avaliação do fenómeno, para o qual a visão institucional e interventiva da sociologia da educação fortemente contribuiu. Na verdade, o Observatório, entretanto já extinto, foi na altura coordenado por uma equipa de sociólogos da área da educação, e da sua atividade principal resultaram, entre outros, vários relatórios, recomendações e toda uma gama de produtos científicos (artigos, capítulos de livros, conferências). Entendido na interseção de problemáticas diversas, e num quadro articulado de políticas sectoriais, esta solicitação ocorreu num espaço de intensa discussão política e social e integrou outras preocupações, como a promoção da efetiva igualdade de oportunidades educativas; a articulação da intervenção interministerial na área da segurança escolar e a modernização e qualificação dos processos de produção e uso de informação pelo ministério da educação (ME) nos processo de decisão política e administrativa (Rodrigues, 2010). Dentro desta lógica, o OSE participou ativamente na construção de instrumentos de monitorização das situações de violência, na reestruturação e preparação de outras intervenções de apoio à política educativa, contribuindo para uma sistematização das situações de violência no sistema educativo, proposta enquadrada numa estratégia de reorganização do sistema e de promoção da equidade educativa (Sebastião, 2013). Posicionado institucionalmente próximo do poder executivo, constituiu um desafio relativamente à forma como a investigação científica e a atividade pericial precisam de conviver para poderem contribuir efetivamente para o suporte das políticas públicas.

Os desafios resultantes da construção do observatório traduziram-se pela forma como a construção de uma problemática científica sobre a violência na escola se confronta com as conceções sociais, políticas e mesmo culturais existentes sobre o que são e como devem ser as relações entre os diversos atores sociais presentes no contexto institucional escolar.

Muitas das conceções explicativas sobre as causas das situações de violência nas escolas insistem em perspetivas de pendor individualista e patológico, constituindo um argumento central da crítica conservadora à escola pública. 
A atuação dos sociólogos num contexto de intensa politização passou por isso pela construção de um aparato teórico e metodológico capaz de responder aos sucessivos questionamentos políticos e mediáticos, mostrando a importância da utilização de conceitos cientificamente construídos e testados, em estreita articulação com a investigação empírica e a difusão sistemática e controlada dos resultados.

A investigação científica e a criação do OSE em 2005, em cooperação estreita com o Programa Escola Segura, permitiram conhecer melhor os fenómenos relacionados com a segurança dos estabelecimentos de ensino e fornecer indicadores cientificamente aferidos, que contribuíram para mostrar que as situações de violência na escola radicavam de facto no seu interior e resultavam em grande parte da própria lógica escolar.

A atividade de recolha de informação desenvolvida pela equipa do OSE resultou de uma combinatória de métodos extensivos e qualitativos, tendo a análise da difusão das situações de violência contemplado diferentes níveis analíticos, tendo como objetivo a recolha e análise de dados nacionais em todas as escolas públicas.

A informação recolhida permitiu analisar a distribuição das situações de violência a nível nacional, mostrando ser um fenómeno relativamente restrito. Permitiu igualmente constatar a existência de acentuadas assimetrias regionais, com uma elevada concentração de ocorrências num número relativamente limitado de concelhos e escolas.

Passámos assim a poder utilizar informação de tipo variado, de forma a construir progressivamente uma visão objetivada do tipo e extensão das situações de violência encontradas, constituindo os dados recolhidos de forma sistemática a única informação extensiva disponível a nível nacional. A sua análise pelo O SE possibilitou pela primeira vez mapear a difusão e evolução das ocorrências registadas por região e por escola em Portugal (Sebastião, Campos e Merlini, 2010). Com base neste conhecimento e partindo da identificação de grandes disparidades entre escolas com perfis semelhantes foi posteriormente realizada uma abordagem centrada nas escolas e territórios educativos através da realização de estudos de caso, tomando como objeto de estudo central as suas dinâmicas organizacionais de gestão da disciplina.

Foi assim possível desconstruir muitas das conceções de senso comum sobre a difusão de situações de violência nas escolas portuguesas, facto que, em articulação com a implementação articulada de medidas de política de segurança e de educação para a cidadania nas escolas contribuíram para uma efetiva redução das situações de violência nas escolas.

\section{b) Elaboração de Cartas Educativas (CEM) e Projetos Educativos Municipais}

A Carta Educativa é um instrumento concelhio de planeamento/(re)ordenamento urbano e educativo, com enquadramento legal obrigatório no âmbito da política estratégica educativa dos diferentes municípios Portugueses. Evoluiu ultimamente de acordo com a atual tendência de descentralização das políticas educativas, pautando-se por diferentes objetivos (uns mais de planeamento, outros mais de ação) e convocando diferentes atores e campos científicos do saber. Neste quadro, e dada a própria transformação do instrumento ao longo dos últimos anos, não se limita agora a confrontar projeções demográficas com equipamentos de modo prever investimentos na rede escolar, apresentando uma vertente estratégica e prospetiva mais forte 
com incidência nos processos educativos, na medida em que muitos municípios requerem a elaboração de Planos Educativos Estratégicos Concelhios, que visam definir a intervenção dos municípios e de outros agentes locais nos processos educativos, em articulação com as escolas. Boa parte destes novos instrumentos estratégicos de envolvimento municipal na educação têm contado com a participação ativa de sociólogos nas equipas a quem são dirigidas as encomendas para a respetiva elaboração.

Os desafios têm sido vários: desde logo, porque as CEM representam elas próprias um elemento mediador entre os serviços políticos centrais e as instâncias municipais; depois, porque preveem o envolvimento e valorização do papel das comunidades educativas como um todo, obrigando a uma minuciosa tarefa de auscultação e de mediação entre figuras institucionais nem sempre consonantes nas visões e nos interesses específicos, facto que tem gerado uma situação de isolamento e de falta de articulação entre si. Falamos, por exemplo, de diretores de escolas que querem ver os seus equipamentos melhorados e a rede reordenada; os serviços municipais de Educação, preocupados com a eficiência das iniciativas a implementar, em corresponder aos parâmetros estabelecidos a nível central e em abrir um novo espaço de competências políticas próprias; os pais, preocupados com a qualidade e proximidade das escolas, que querem também participar ativamente da planificação; Juntas de Freguesia que se encontram confrontadas com uma grande falta de recursos próprios para apoiar as escolas em matérias da sua responsabilidade (pequenas obras e reparações, por exemplo); os agentes de segurança preocupados com as matérias de violência e segurança nas escolas e nos espaços circundantes; as empresas, no sentido de se envolverem mais efetivamente na criação de condições para uma oferta educativa de qualidade; com associações e outros serviços, como museus ou estruturas culturais, com potencial educativo e, por vezes, promotores de serviços educativos; Centros de Saúde, responsáveis pelo apoio técnico na educação para a saúde; com os serviços sociais que lidam com famílias desfavorecidas, etc., entidades estas que devem ser envolvidas na partilha de objetivos e recursos para um domínio institucional, a educação, com o qual não têm hábitos de relacionamento; e, finalmente, um terceiro elemento prende-se com multidisciplinariedade, sendo um terreno de trabalho partilhado com outras ciências (demografia, geografia, arquitetura) e com as quais a sociologia deve conseguir dialogar e cooperar. Além disso, as Cartas evoluíram para uma dupla função de instrumento de ordenamento prospetivo da relação entre a procura escolar e a capacidade dos equipamentos existentes, e de instrumentos estratégicos de desenvolvimento de projetos educativos municipais, o que implica um alargamento do seu âmbito de incidência para matérias até há pouco exclusivas do sistema de educação, como os currículos e as ofertas extracurriculares, a coordenação da oferta e a reconfiguração dos projetos de escola, entre outros.

Por estas razões, e pela natureza metodológica das CEM, considera-se determinante a perspetiva científica sociológica, por quatro razões principais: (1) o conhecimento das diferentes problemáticas da educação, o que permite incorporar nas Cartas e nos Planos uma visão crítica, fruto da reflexão mais informada entre os agentes envolvidos; (2) a desmistificação de crenças sobre os processos educativos e as prioridades da educação, trazendo rigor para o processo de construção de sistemas locais capazes de responder às necessidades educativas de cada território concelhio; (3) a competência relacional que torna possível promover o diálogo construtivo entre os diversos agentes; (3) as competências técnicas para o tratamento de dados estatísticos, condução 
de entrevistas, dinamização de focus-groups, realização de questionários, apresentação de resultados de investigação e de negociação política entre agentes; (4) o domínio das metodologias de avaliação, dado que a revisão de cada Carta Educativa implica a verificação dos resultados e dos resultados da anterior, bem com a aferição dos fatores que fizeram com que os seus objetivos fossem alcançadas, e em que medida..

A experiência mostra que não há dois processos iguais quando nas equipas técnicas responsáveis pela elaboração das propostas de Carta Educativa e de Projeto Educativo concelhio prevalece uma atitude sociológica. No caso contrário, essas ferramentas de planeamento educativo e de descentralização acabam por assumir uma natureza burocrática, uniforme, estandardizada, estereotipada, que cumpre critérios meramente formais, mas não libertam energias nem permitem tirar partido das forças locais. A intervenção da sociologia implica considerar e estudar cada concelho como um caso singular, e os produtos são «taylor-made», feitos peça a peça, não apenas porque as condições objetivas e os problemas são diferentes, mas também porque são diversas as perspetivas de cada agente envolvido e os consensos e controvérsias que se geram, e cuja gestão faz parte do próprio processo de produção.

Nestes projetos a interação entre os sociólogos e os decisores é muito próxima, embora os papéis estejam claramente segregados. Trata-se, na verdade, de processos que se aproximam muito da investigação-ação, na medida em que a abordagem científica aos problemas se cruza com competências operacionais para construir propostas de ação discutidas, aferidas e, por vezes, parcialmente implementadas pelos responsáveis dos municípios e pelos restantes agentes educativos.

\section{Estudo de avaliação prospetivo: Redução da dimensão das turmas}

O terceiro exemplo respeita a um estudo prospetivo, encomendado em 2017 pelo Ministério da Educação (ME) a uma equipa de peritos e consultores da área da sociologia, com apoio de economistas e metodólogos, com vista a avaliar os impactos pedagógicos e financeiros da redução do número máximo de alunos por turma a nível nacional. A medida da redução constava do programa de governo e o ME pretendia saber qual o esforço financeiro envolvido e se esse esforço seria compensado pelos ganhos na melhoria das práticas pedagógicas e dos consequentes resultados escolares.

A medida gerava dois tipos de controvérsia, uma política e outra científica. No plano político o problema levantou-se quando o governo do período de intervenção da Troika (formada pelo BCE, pelo FMI e pela CE) em Portugal, levando a cabo a lógica da austeridade, decidiu aumentar em cerca de dois alunos a dimensão das turmas (com algumas exceções, como fossem a das turmas com alunos com necessidades educativas especiais cujo Plano de Educação Especial previsse a integração numa turma mais reduzida e a dos cursos de cariz profissionalizante.

O governo eleito em 2015 propôs-se reverter a austeridade. Foi nesse quadro que incluiu no Programa a redução do número de turmas. A medida gerou um debate político aceso, estimulado em boa parte pelo Conselho Nacional de Educação (CNE, presidido por um destacado dirigente de um partido da oposição de centro-direita, partido esse que se pronunciou contra a redução) que publicitou um estudo que apresentava custos elevadíssimos e salientava a nulidade dos impactos pedagógicos. Do lado dos sindicatos de professores e das escolas, pelo contrário, era sistematicamente referida como obstáculo à promoção do sucesso escolar a dimensão excessiva das turmas. 
O estudo prospetivo encomendado pelo ME mostrou que: (1) o CNE não tinha feito as contas contabilizando as turmas que já tinham dimensão inferior ao limite legal proposto (repondo os parâmetros anteriores à Troika), pelo que o custo efetivo era seis vezes inferior ao que tinha calculado. E além disso não retirava a esses custos as receitas diretas e indiretas do Estado relativas aos impostos que incidiam sobre os salários a pagar aos professores eventualmente a contratar (na verdade a probabilidade de não ser necessário contratar nenhum era fortíssima, dada a queda abrupta nas taxas de natalidade e no número de alunos), quer sobre o consumo resultante desses rendimentos; (2) por outro lado, a grande maioria das turmas já tinha dimensões mais reduzidas do que o previsto na legislação, quer devido à adoção de estratégias de dispersão dos alunos com NEE redutores de dimensão das turmas, quer por rarefação dos alunos, pelo que não era a dimensão das turmas o obstáculo que se dizia ser à adoção de estratégias pedagógicas promotoras do sucesso escolar.

Vale a pena introduzir aqui uma nota relativa à dificuldade que a sociologia muitas vezes encontra quando envolvida no contributo para a tomada de decisão política. Este estudo foi um exemplo de como o poder, que encomenda os estudos, muitas vezes pretende intervir no trabalho técnico-científico das equipas, se não tentando influenciar os seus resultados, pelo menos neste caso procurando impedir que ele pudesse explorar todas as dimensões relevantes, como a do planeamento da constituição das turmas nas escolas, ou a da forma de calcular os custos salariais de uma medida de política que implica a contratação de pessoal. Nesses casos o sociólogo vê-se confrontado com três opções: ou cede às pressões, o que é reprovável no plano ético; ou abandona o estudo, o que é o desperdício de uma oportunidade de investigar um tema de grande interesse; ou resiste e negoceia a sua autonomia, por exemplo, como foi o caso, produzindo relatórios em que apenas publica parte das descobertas realizadas, remetendo para publicações científicas a parte mais fina do seu trabalho. Foi esta a opção com(seguida).

E de facto valia a pena, no plano do debate científico sobre a matéria, ir aos detalhes a que se foi, pois julga-se que se conseguiram evidências relevantes para o saber nesta área.

As controvérsias científicas giram em torno de dois polos opostos. Algumas pesquisas com natureza mais econométrica apontam para a ausência de efeitos da dimensão de turma nos resultados escolares, ou alternativamente sublinhavam a insignificância dos impactos pedagógicos das turmas com dimensão reduzida, perante um cenário de progressivo incremento dos custos para o Estado; por outro lado, e em sentido contrário, dos principais estudos de referência conduzidos durante as décadas de 80 e 90 (Finn e Achilles, 1990; Mueller, Chase e Wolden, 1988) chegam evidências justamente sobre os impactos e ganhos pedagógicos com a redução da dimensão das turmas, sobretudo considerando os alunos provenientes de meios socioeconomicamente mais desfavorecidos (os quais, segundo esses estudos, beneficiam de turmas com menor dimensão).

A consideração das duas posições obrigou à convocação de metodologias e técnicas diferenciadas na análise das estatísticas e à integração da economia da educação no corpo da análise realizada, bem como à condução prévia de um estudo prospetivo demográfico. As próprias conclusões da investigação (e a visão holística) ilustram bem este esforço sinérgico e combinatório. Vejamos algumas:

A análise realizada confirmou as conclusões dos grandes estudos que apontam para as vantagens de turmas mais pequenas. Foram realizados vários exercícios e aplicados modelos estatísticos que visaram esclarecer sobre a ordem de relação entre a dimensão de turma e os resultados escolares/impactos pedagógicos. Por um lado, várias correlações foram estabelecidas entre a variável dimensão média de turma - considerando vários 
níveis do ensino básico - e alguns indicadores de desempenho escolar (como as taxas de repetição totais e para segmentos específicos da população escolar e o abandono escolar), para vários países europeus, entre os quais Portugal, a partir de dados da OCDE (PISA). Genericamente estes exercícios mostraram que às turmas com menor dimensão estava associada uma maior probabilidade de transição/conclusão de ano, especialmente considerando os anos escolares iniciais e o estatuto socioeconómico dos alunos, beneficiando o desempenho escolar dos alunos com origens socioeconómicas mais desfavorecidas, em especial no $6^{\circ}$ ano e no $9^{\circ}$ ano do Ensino Básico.

A conclusão chave apontava para o efeito negativo do aumento da dimensão de turma no desempenho escolar dos alunos e na qualidade das aprendizagens no Ensino Básico. Também chegaram a ser considerados outros fatores verificando-se, por exemplo, que os alunos que frequentavam escolas integradas em Territórios Educativos de Intervenção Prioritária apresentavam tendencialmente piores resultados ou que as turmas mais pequenas tendiam a apresentar melhores resultados nos exames de matemática e português e, consequentemente, a promover uma redução da reprovação escolar.

O tipo de análises então conduzidas e as teorias mobilizadas serviram de suporte ao trabalho posteriormente executado pelos especialistas em economia da educação. A decisão de reduzir ou não a dimensão das turmas tem sobretudo objetivos de política educativa, tendo sido ponderados na decisão que o governo acabou por tomar, seguindo as recomendações dos investigadores, tanto os efeitos pedagógicos, como os custos da medida. Os cálculos de custos apresentados consideraram os custos brutos da medida de política, estimando-os partir da confrontação entre cenários de redução do número de alunos por turma e cenários de não redução (ou cenário de partida), mas apenas depois de identificado o número de turmas que, realmente, poderia ver o número de alunos reduzido. Para além disso, a equipa realizou cálculos segundo diferentes modelos que estimassem não os custos brutos, mas os custos líquidos do aumento real de turma previsto (Mucharreira, Cabrito e Capucha, 2019). De uma maneira geral, concluiu-se que os ganhos pedagógicos compensariam os custos efetivos da media.

Finalmente, e a partir dos pontos acima destacados, podemos ainda sublinhar, para efeito dos desafios aqui a considerar, dois pontos: a) a própria pressão política e pública desta medida, tendo sido fortemente debatida no campo político-mediático, facto que pode contaminar, como bem sabemos, a condução da atividade pericial; e b) a responsabilidade, sabendo-se ser uma medida potencialmente transformadora das lógicas pedagógicas e organizativas escolares com grande impacto, o resultado final foi alvo de um processo longo de negociação, de adaptação e de afinação das conclusões encontradas.

\section{Conclusões}

Partimos nesta pesquisa de uma premissa que carece de investigação: a sociologia, quer como ciência, quer como profissão, é crescentemente chamada a tomar parte nos processos de tomada de decisão e de execução de políticas públicas de educação.

Não é uma novidade a interseção entre a ciência sociológica e a política neste domínio. Os sociólogos estiveram na primeira linha da crítica às perspetivas funcionalistas sobre o papel da escola, ao chamar a atenção para os problemas da relação entre desigualdades socioculturais e desigualdades escolares, as suas causas e as suas consequências. Com isso deram origem a um enorme movimento de reformas políticas visando a mudanças no sentido de promover a equidade e a justiça na educação.

O envolvimento entre a sociologia e os sistemas educativos, com os seus diferentes agentes, nunca mais deixou de ser notório e relevante. Esse envolvimento assume uma diversidade de formas, que vão 
da realização de estudos e avaliações até à participação prática de sociólogos nos processos educativos, aos mais diversos níveis do sistema, muitas vezes incluídos em equipas multidisciplinares. Os contributos foram também muito diversos, desde o apoio à formulação de políticas, à crítica das situações problemáticas que persistem e de outras que emergem, passando pelo contributo dado ao conhecimento por parte dos agentes acerca das realidades que o senso comum oculta, ao desenvolvimento do sentido crítico e da capacidade de negociação e cooperação entre esses agentes.

Procurou-se com os exemplos apresentados, e com a breve discussão anteriormente realizada, colocar em evidência a importância da construção de problemáticas sociológicas como determinante na relação entre a atividade dos sociólogos da educação e a produção e implementação de políticas públicas. Podemos destacar a capacidade de olhar para os sistemas no seu conjunto (estruturas e práticas), de colocar os sistemas e os atores em perspetiva; de mediar as relações entre atores com interesses descoincidentes, usando a evidência como ferramenta básica; a convocação das teorias da educação e as vantagens do domínio dos métodos e técnicas de pesquisa, incluindo no quadro de abordagens multimétodo; e, por fim, a evocação paradigmática da noção de «imaginação sociológica» (Mills, 1982), o que significa atender aos contextos, à diversidade cultural, às coordenadas de tempo e espaço, e à remissão dos fenómenos particulares para o sistema global de atores e políticas que lhes conferem inteligibilidade crítica. Mas significa também a assunção clara de um compromisso ético inequívoco com o direito de todos e de cada um a uma educação de qualidade.

Como afirmou Carol Weiss «... há a possibilidade de envolvimento com a ação política requerente de uma proximidade que não implique compromisso ou coligação. Pode existir uma sociologia crítica vigorosa, independente, original, ousada, que proporcione ao governo informação e críticas, uma sociologia capaz de escapar às assunções da direita ou da esquerda. Não se trata de uma raridade. É um tipo de sociologia que muitos sociólogos praticam. Mas à qual falta frequentemente dois elementos cruciais: (i) um esforço sustentado para atingir as audiências políticas com as mensagens sociológicas, isto é, que preste séria atenção à disseminação, ao contacto e ao diálogo contínuo com os atores do processo politico, ou a utilização de instituições intermediárias que promovam essa tarefa; (ii) (2) reconhecimento de que a sociologia tem mais para oferecer às audiências políticas do que dados validados produzidos a partir de experiências e estudos bem desenhados. Apesar dos dados de qualidade serem úteis e construírem credibilidade, igualmente importante é a perspetiva sociológica incorporada nas entidades, nos processos e nos eventos. Os participantes no processo politico podem beneficiar da compreensão das forças e correntes que moldam os eventos, e das estruturas de significado que os sociólogos retiram das suas teorias e investigações» (Weiss, 1993: 37).

\section{Referências bibliográficas}

Bache, Ian (2013): "Measuring quality of life for public policy: an idea whose time has come? Agenda-setting dynamics in the European Union". Journal of European Public Policy, 20 (1), 21-38.

Beck, Ulrich (1992). Risk Society: Towards a New Modernity. London: Sage Publications.

Burawoy, Michael (2009): “The Public Sociology Wars” en Vincent Jeffries (ed.): Handbook Of Public Sociology. New York: Rowman \& Littlefield Publishers.

Coleman, James S. (1994): “A Vision for Sociology”. Society, 32 (1), 29-34.

Finn, Jeremy D. y Achilles, Charles M. (1990): "Answers and questions about class size: A statewide experiment”. American Educational Research Journal, 27 (3), 557-577. 
Fischer, Frank (2009). Democracy and Expertise. Reorienting Policy Inquiry. Oxford: Oxford University Press. Giddens, Anthony (1992). As consequências da modernidade. Lisboa: Celta Editora.

Maasen, Sabine y Weingart, Peter (2005): “What's new in scientific advice to politics?” en Sabine Maasen y Peter Weingart (ed.): Democratization of Expertise? Exploring Novel Forms of Scientific Advice in Political Decision-Making. Springer: Dordrecht.

Mills, Charles Wright (1982). A Imaginação sociológica. Rio de Janeiro: Zahar Editores.

Mucharreira, Pedro Ribeiro; Cabrito, B. y Capucha, Luís Antunes (2019): "Impactos financeiros de uma política de redução do número de alunos por turma: o caso Português”. Educação (UFSM), 44 (1), 1-20.

Mueller, D. J., Chase, C. I. y Walden, J. D. (1988): "Effects of reduced class size in primary classes". Educational Leadership, 45, 48-50.

Ramos, Madalena; Capucha, Luís y Tavares, Inês (org.) (2018). Quem são e o que fazẹm os sociólogos em Portugal?. Lisboa: Editora Mundos Sociais.

Rodrigues, Maria de Lurdes y Silva, Pedro Adão (2012). Políticas Públicas em Portugal. Lisboa: Imprensa Nacional Casa da Moeda/ISCTE-IUL.

Rodrigues, Maria de Lurdes (2010). A Escola Pública Pode Fažer a Diferença. Coimbra: Almedina.

Sebastião, João (2013). "Violência na escola, processos de socialização e formas de regulação". Sociologia, Problemas e Práticas, 71, 23-37.

Sebastião, João; Campos, Joana y Merlini, Sara (2010): "Relatório de Segurança Das Escolas Portuguesas 2010-2011”. Observatório de Segurança Escolar/Ministério da Educação. https://www.researchgate. net/publication/330754338_RELATORIO_DE_SEGURANCA_DAS_ESCOLAS_PORTUGUESAS_2010-2011.

Silva, Augusto Santos (2017): "Sociologia e política pública: sobre avanços recentes em Portugal”. Análise Social, 225, lii (4. $\left.{ }^{\circ}\right), 782-803$.

Silva, Augusto Santos (2006). A Sociologia e o Debate Público. Estudos sobre a relação entre o conhecer e o agir. Porto: Edições Afrontamento.

Stehr, Nico (1994). Knowledge Societies. London: Sage.

Weiss, Carol H. (1993): “The Interaction of the Sociological Agenda and Public Policy” en William Julius Wilson (ed.): Sociology and the Public Agenda. SAGE Publications: Newbury Park, California.

\section{Notas biográficas}

João Sebastião es sociólogo, doctor en Sociología, es profesor titular del ISCTE-Instituto Universitário de Lisboa e investigador del Centro de Investigação e Estudos de Sociologia-IUL, del que es director desde 2014. Ha trabajado activamente como experto en el área de la violencia escolar con la Unión Europea y el Consejo de Europa y en estudios de alfabetización de adultos para la OCDE y la UE. Coordinó el Observatorio de Seguridad Escolar del Ministerio de Educación. Sus principales áreas de investigación son las desigualdades sociales en la educación, las políticas educativas, la violencia en la escuela y las organizaciones escolares. Es autor de varios artículos en revistas científicas, capítulos de libros y libros nacionales e internacionales. 
Luís Capucha es profesor titular del ISCTE-Instituto Universitário de Lisboa e investigador del Centro de Investigação e Estudos de Sociologia-IUL. Fue Director General de Planificación del Ministerio de Trabajo y Seguridad Social, coordinador del Plan Nacional de Empleo, Director General de Innovación y Desarrollo Curricular del Ministerio de Educación y Presidente de la Agencia Nacional de Calificación. Actualmente es Director del Departamento de Ciencia Política y Políticas Públicas del ISCTE-IUL. Miembro del Consejo Nacional de Educación. Sus áreas de interés son las políticas públicas, la educación y la formación, el empleo, las culturas populares y las metodologías de planificación y evaluación.

Susana da Cruz Martins es socióloga, doctora en Sociología. Profesora asistente del ISCTE- Instituto Universitário de Lisboa e investigadora del Centro de Investigação e Estudos de Sociologia (CIES). Es miembro del Observatorio de Desigualdades y Directora del Máster en Administración Escolar (en el ESPP, ISCTE). Recibió una beca postdoctoral de la Fundación para la Ciencia y la Tecnología y una Cátedra Gulbenkian de F. C. Gulbenkian. Ha participado y coordinado proyectos de investigación nacionales e internacionales. Coordina en Portugal el proyecto europeo Eurostudent - Social and Economic Conditions of Student Life In Europe, en las ediciones II, III, VI. Es autora de varias publicaciones nacionales e internacionales, principalmente en los ámbitos de las políticas de educación y de enseñanza superior, los sistemas de educación comparada y las desigualdades sociales.

Ana Rita Capucha es socióloga, máster y doctoranda en Sociología ISCTE-IUL. Asistente de investigación en el CIES-IUL desde 2013, habiendo participado en varios proyectos de investigación aplicada (nacionales y uno internacional) y en iniciativas de divulgación científica, especialmente en las áreas de sociología de la educación y política pública y evaluación de medidas de política educativa. Actualmente es becaria de doctorado (por la Fundación para la Ciencia y la Tecnología), desarrollando un proyecto de investigación sobre la autonomía escolar, el éxito educativo y la promoción de la equidad. 